\title{
Características de carcaça e qualidade de carne de cabritos Saanen alimentados com ração completa farelada, peletizada e extrusada
}

\author{
Carcass characteristics and meat quality of Saanen kids fed ground, pelleted and extruded total ration
}

\author{
Cecília Maria Costa do Amaral ${ }^{\mathrm{I}}$ Elisabete Regina Leone Pelicano ${ }^{\mathrm{II}}$ Enrique Alejandro Yañez ${ }^{\mathrm{III}}$ \\ Hirasilva Borba Alves de Souza' ${ }^{\text {II }}$ Márcia Rita Fernandes Machado ${ }^{\mathrm{I}}$ Atushi Sugohara ${ }^{\mathrm{IV}}$ \\ Kleber Tomás de Resende ${ }^{\mathrm{IV}}$
}

\section{RESUMO}

O objetivo deste estudo foi avaliar os efeitos da extrusão e peletização de ração completa farelada, sobre as características de carcaça e qualidade de carne de cabritos Saanen abatidos aos 30, 45 e 60 dias de idade, distribuídos em delineamento inteiramente casualizado. Verificou-se que os processos de extrusão e peletização de ração completa não influenciaram o rendimento de carcaça, área de olho de lombo, peso de lombo, pescoço e as características físico-químicas da carne. Cabritos que receberam ração completa peletizada tiveram, aos 60 dias de idade, maior peso final, peso de carcaça fria e pesos de paleta, costilhar e perna. Com relação ao efeito da idade, animais com 60 dias apresentaram carne com maior teor protéico e menor $\mathrm{pH}$ final, inferindo-se que esta seria a idade de abate mais adequada dentre as idades avaliadas.

Palavras-chave: caprinos, carne caprina, cortes comerciais, processamento de ração.

\section{ABSTRACT}

The study was aimed at evaluating the effects of ground total ration, pelleted total ration or extruded total ration intake on carcasses characteristics and meat quality of the Saanen kids slaughtered at 30, 45 and 60 days of age, according to a completely randomized design. The extrusion and pelleting process did not affect the dressing percentage values, loin eye area, loin and neck weight and the physico-chemical characteristics of the meat. Kids fed with pelleted total ration, showed higher live weight, carcass, shoulder, ribs and leg weight. In relation the effect of age, animals at 60 days, showed meat with greater protein value and lower final $\mathrm{pH}$, then, we conclude that 60 days is the best age to kids slaughetered, related with the ages evaluated.
Key words: goats, meat goat, commercial cuts, ration
processing.

\section{INTRODUÇÃO}

A carne caprina é um produto com grande potencial comercial, considerando os promissores mercados interno e externo. Além disso, a globalização poderá possibilitar a conquista de novos nichos de mercado e impulsionar o consumo (EMBRAPA, 2003). No Brasil, há uma tendência de elevação da produção, principalmente, com a inserção de novos Estados e regiões não consideradas produtores tradicionais, verificando-se ainda aumento do consumo na região Sudeste do país (SILVA, 2002).

Nos últimos anos, o interesse pela carne de caprinos tem crescido em função de suas propriedades, pois é uma fonte protéica de alto valor biológico. Possui percentuais de gordura saudáveis, isto é, com elevada relação ácidos graxos insaturados/saturados e concentração reduzida de colesterol (MADRUGA, 1999). Além disso, caracteriza-se por ser uma carne magra, pois no processo de evisceração a maior parte da gordura é extraída. Em caprinos, $45 \%$ da gordura corporal é armazenada nas vísceras. Já em bovinos e ovinos, essa porcentagem é de somente $25 \%$ (POTCHOIBA et al., 1990).

IDepartamento de Morfologia e Fisiologia Animal, Faculdade de Ciências Agrárias e Veterinárias (FCAV), Universidade Estadual Paulista (UNESP), Campus de Jaboticabal. Rua 24 de maio, 859, 14870-350, Jaboticabal, SP, Brasil. E-mail: cmcamaral@netsite.com.br. Autor para correspondência.

IIDepartamento de Tecnologia, FCAV, UNESP, Jaboticabal, SP, Brasil

IIIDepartamento de Producción Animal, Facultad de Ciencias Veterinarias, UNNE, Corrientes, Argentina.

${ }^{\text {Iv }}$ Departamento de Zootecnia, FCAV, UNESP, Jaboticabal, SP, Brasil 
Diversos tratamentos físicos, tais como extrusão e peletização, são utilizados no processamento de rações, com o objetivo de incrementar a eficiência de utilização. Entretanto, são escassas as informações sobre o efeito do fornecimento dessas rações processadas nas características da carcaça e da carne de caprinos. MORAND-FEHR \& LEBBIE (2004) verificaram que, do total dos artigos publicados durante os quatro primeiros meses de 2000 (banco de dados $\mathrm{CAB})$, apenas $2,7 \%$ avaliaram a carne caprina.

A alimentação em sistemas intensivos de produção representa de 55 a 75\% dos custos totais de produção (HADJIPANAYIOTOU, 1987). Assim, a avaliação de diferentes rações e de seus efeitos tornase imprescindível nos sistemas de produção. O objetivo deste trabalho foi avaliar os efeitos do fornecimento de ração completa farelada, peletizada ou extrusada sobre as características de carcaça e na qualidade da carne de cabritos Saanen abatidos aos 30, 45 e 60 dias de idade.

\section{MATERIAL E MÉTODOS}

No experimento, foram utilizados caprinos Saanen não-castrados, distribuídos nos seguintes tratamentos: ração completa farelada (RCF), adotada como controle, ração completa peletizada (RCP) e ração completa extrusada (RCE). Doze cabritos (quatro por tratamento) foram abatidos aos 30, 45 e 60 dias de idade, perfazendo um total de trinta e seis animais.

Os animais foram separados das mães após o nascimento e receberam colostro bovino durante os primeiros três dias de vida. Após esse período, foram alimentados com sucedâneo de leite e desmamados aos 45 dias de idade. O fornecimento de alimentação sólida iniciou-se após 15 dias de idade e os animais receberam ração duas vezes ao dia.

As rações apresentaram a mesma composição: feno da parte aérea do milho (40,0\%), milho grão moído (29,3\%), farelo de soja (21,8\%), melaço $(4,8 \%)$, óleo de soja $(0,9 \%)$ e minerais $(3,2 \%)$. A composição bromatológica (\% matéria seca) das rações RCF, RCP e RCE foi de 16,5; 16,9 e 16,5\% de proteína bruta; 34,5; 27,8 e 32,0\% de fibra detergente neutro; 19,9; 20,3 e 18,4\% de fibra detergente ácido e 8,9; 9,1 e $8,6 \%$ de extrato etéreo, respectivamente. As rações foram formuladas para proporcionarem um ganho de $150 \mathrm{~g}$ por dia, de acordo com AFRC (1998), e processadas de acordo com AMARAL et al. (2005).

Os cabritos foram alojados em gaiolas individuais, cujo piso era ripado, com comedouros individuais e bebedouro para cada dois animais. Os animais foram pesados ao nascimento e uma vez por semana, pela manhã. Permaneceram em jejum sólido e líquido durante 24 e 16 horas, respectivamente, antes do abate. Encerrado o período de jejum, os animais foram retirados das gaiolas, pesados para determinação do peso vivo em jejum (PJ) e imediatamente conduzidos para sala de abate, localizada em anexo à instalação dos animais, não havendo necessidade de transporte. Imediatamente após o abate, procedeu-se à sangria, à esfola e à evisceração. Para cálculo do peso de corpo vazio (PCV), foram subtraídos o conteúdo do trato gastrointestinal, da bexiga urinária e da vesícula biliar. O peso de carcaça quente (PCQ) foi obtido mediante pesagem da carcaça, que foi separada das patas nas articulações carpo-metacarpiana e tarsometatarsiana, retirando-se também os rins, a gordura perirenal e o diafragma.

As carcaças foram transportadas, dentro de bandejas plásticas, para o laboratório (localizado a 800m do local do abate) para determinação do pH e avaliação da cor, realizadas aproximadamente 15 minutos após o abate. Em seguida, foram resfriadas em câmara fria a $4^{\circ} \mathrm{C}$, durante 24 horas, sendo novamente pesadas para obtenção do peso de carcaça fria (PCF), determinandose também o $\mathrm{pH}$, a porcentagem de queda do $\mathrm{pH}$ e a cor da carcaça resfriada.

A determinação do $\mathrm{pH}$ da carne foi realizada com o auxílio de um peagômetro digital da marca Jonhis, modelo IpHPJ, e a cor foi determinada mediante utilização de colorímetro Minolta Chroma Meter, onde foram avaliados os parâmetros L* (luminosidade), a* (intensidade de vermelho) e b* (intensidade de amarelo) do Sistema CIELAB. A capacidade de retenção de água (CRA) foi calculada de acordo com metodologia proposta por HAMM (1960), e as análises de composição centesimal das amostras foram efetuadas segundo as técnicas preconizadas pelo AOAC (1990). Para a realização das análises de $\mathrm{pH}$, cor, CRA e análise centesimal, foram colhidas amostras do músculo semimembranoso dos animais, que corresponde ao corte comercial denominado coxão mole.

As carcaças foram divididas longitudinalmente, sendo obtido o peso da meia carcaça esquerda (PME); esta foi seccionada em cinco regiões: paleta, pescoço, costilhar, lombo e perna, as quais foram separadas e pesadas em balança digital com precisão de $0,01 \mathrm{~g}$. Na secção entre a $13^{a}$ vértebra torácica e a 1a lombar, foi determinada a área de olho de lombo (RESENDE et al., 2004a) e, mediante esse valor, foi estabelecida uma relação AOL/PCQ. Foram determinados os rendimentos de carcaça quente (RCQ) como sendo o PCQ/PJ*100, comercial (RCC) igual a PCF/PJ*100 e biológico (RB), que é a relação entre $\mathrm{PCQ} / \mathrm{PCV}^{*} 100$. 
O delineamento experimental utilizado foi inteiramente casualizado, em esquema fatorial $3 \times 3$ (três idades e três rações), com quatro repetições. Os dados foram submetidos à análise de variância pelo teste F e as comparações das médias foram realizadas pelo teste de Tukey, a 5\% de probabilidade de erro, e analisadas no programa estatístico SAS (2001).

\section{RESULTADOS E DISCUSSÃO}

Para PJ, PCF, PME e pesos de paleta, costilhar e perna, a interação entre idade e processamento de ração foi significativa e os valores dos desdobramentos das médias encontradas são apresentados na tabela 1 . Cabritos com 60 dias de idade alimentados com RCP apresentaram maior ingestão de matéria seca, maior ganho de peso diário e, conseqüentemente, maior peso final em relação aos que receberam RCF ou RCE. Também foi observado nos animais de 60 dias de idade, alimentados com RCP, neste experimento, maiores PJ, PCF, PME e pesos de paleta, costilhar e perna, em relação aos animais alimentados com RCE ou RCF. Não ocorreu diferença significativa entre rações para essas variáveis, em animais de 30 e 45 dias de idade. Já o lombo e o pescoço apresentaram maior peso em animais de 60 dias de idade e não diferiram entre as rações avaliadas.
Segundo YÁÑEZ (2002), o pescoço, as costelas e o lombo apresentaram pesos iguais ou inferiores a $0,5 \mathrm{~kg}$ em animais entre 11 e $21 \mathrm{~kg}$, sendo considerados pequenos para sua manipulação, comercialização e aplicação culinária. Esse autor sugeriu que em carcaças com menos de $12 \mathrm{~kg}$, fossem realizados os seguintes cortes: perna, paleta, costilhar (incluindo costelas, peito/fralda e lombo) e pescoço, sendo este último separado da carcaça.

Analisando a soma das porcentagens de perna, paleta e lombo, cortes de maior valor comercial, verificou-se que não ocorreu influência $(\mathrm{P}>0,05)$ das idades e dos tratamentos para esta soma, a qual representou de 63 a 64\% do PCF, valores estes próximos aos obtidos por YÁÑEZ (2002) em animais com 21kg, alimentados à vontade. Tal fato sugere que, mesmo havendo variação no peso do animal entre 6,8 e 11,8kg, os cortes de maior valor comercial mantiveram as mesmas porcentagens na carcaça. Quanto à soma das proporções da paleta e da perna dos animais de 30 e 60 dias, verificou-se valor de $53,2 \%$, resultado semelhante ao encontrado por COLOMER-ROCHER et al. (1992), que foi igual a $54,8 \%$ em carcaças de $5 \mathrm{~kg}$ de caprinos Saanen machos.

No presente estudo, não ocorreu interação significativa entre idade e ração para os valores de rendimento de carcaça (RC), perda por resfriamento

Tabela 1 - Médias, coeficientes de variação (CV \%) e interação entre idade e processamento de ração (I x R), do peso em jejum (PJ), do peso de carcaça fria (PCF), do peso meia-esquerda (PME) e dos pesos de paleta, costilhar, perna, pescoço e lombo de cabritos Saanen alimentados com ração completa farelada (RCF), peletizada (RCP) ou extrusada (RCE) e abatidos aos 30, 45 e 60 dias de idade.

\begin{tabular}{|c|c|c|c|c|c|c|c|c|c|}
\hline & \multicolumn{3}{|c|}{ Peso animal em jejum (kg) } & \multicolumn{3}{|c|}{ Peso carcaça fria (kg) } & \multicolumn{3}{|c|}{ Peso meia-esquerda (kg) } \\
\hline & 30 & 45 & 60 & 30 & 45 & 60 & 30 & 45 & 60 \\
\hline RCF & 6,63bA & 7,63bA & $10,15 \mathrm{aB}$ & 3,66bA & 3,71abA & $4,55 \mathrm{aB}$ & $1,77 \mathrm{bA}$ & $1,82 \mathrm{bA}$ & $2,27 \mathrm{aB}$ \\
\hline RCP & $6,80 \mathrm{cA}$ & $8,75 \mathrm{bA}$ & $11,78 \mathrm{aA}$ & $3,21 \mathrm{bA}$ & $3,98 \mathrm{bA}$ & $5,62 \mathrm{aA}$ & $1,56 \mathrm{cA}$ & $2,02 \mathrm{bA}$ & $2,80 \mathrm{aA}$ \\
\hline RCE & $7,08 \mathrm{bA}$ & $8,82 \mathrm{aA}$ & $9,78 \mathrm{aB}$ & 3,70aA & $4,10 \mathrm{aA}$ & $4,39 \mathrm{aB}$ & $1,84 \mathrm{aA}$ & $2,01 \mathrm{aA}$ & $2,19 \mathrm{aB}$ \\
\hline \multirow[t]{3}{*}{ CV\% } & & 7,7 & & & 10,0 & & & 10,2 & \\
\hline & \multicolumn{3}{|c|}{ Paleta (kg) } & \multicolumn{3}{|c|}{ Costilhar (kg) } & \multicolumn{3}{|c|}{ Perna (kg) } \\
\hline & 30 & 45 & 60 & 30 & 45 & 60 & 30 & 45 & 60 \\
\hline RCF & $0,33 \mathrm{bA}$ & $0,41 \mathrm{abA}$ & $0,48 \mathrm{aB}$ & $0,41 \mathrm{aA}$ & $0,47 \mathrm{aA}$ & $0,47 \mathrm{aB}$ & $0,54 \mathrm{bA}$ & $0,58 \mathrm{bA}$ & $0,71 \mathrm{aB}$ \\
\hline RCP & $0,34 \mathrm{bA}$ & $0,39 \mathrm{bA}$ & $0,60 \mathrm{aA}$ & $0,39 \mathrm{cA}$ & $0,56 \mathrm{bA}$ & $0,75 a \mathrm{~A}$ & $0,48 \mathrm{cA}$ & $0,62 \mathrm{bA}$ & $0,88 \mathrm{aA}$ \\
\hline RCE & $0,39 \mathrm{aA}$ & $0,41 \mathrm{aA}$ & $0,46 \mathrm{aB}$ & $0,47 \mathrm{aA}$ & $0,54 \mathrm{aA}$ & $0,54 \mathrm{aB}$ & $0,59 \mathrm{aA}$ & $0,64 \mathrm{aA}$ & $0,68 \mathrm{aB}$ \\
\hline \multirow[t]{4}{*}{$\mathrm{CV} \%$} & & 11,7 & & 12,9 & & & 9,5 & & \\
\hline & \multicolumn{9}{|c|}{ Lombo (kg) } \\
\hline & 30 & & 45 & 60 & & RCF & RCP & & \\
\hline & $0,17 \mathrm{~b}$ & & $0,19 \mathrm{~b}$ & $0,25 \mathrm{a}$ & & $0,21 a$ & $0,22 a$ & & \\
\hline \multirow[t]{4}{*}{ CV\% } & & & & & 15,4 & & & & \\
\hline & \multicolumn{9}{|c|}{ Pescoço (kg) } \\
\hline & \multicolumn{3}{|r|}{45} & 60 & \multicolumn{2}{|c|}{ RCF } & RCP & \multicolumn{2}{|c|}{ RCE } \\
\hline & \multicolumn{2}{|l|}{$0,16 b$} & $0,18 b$ & $0,26 a$ & \multicolumn{2}{|r|}{$0,20 \mathrm{a}$} & $0,21 \mathrm{a}$ & \multicolumn{2}{|c|}{$0,19 a$} \\
\hline CV\% & & & & & 18,4 & & & & \\
\hline
\end{tabular}

Médias seguidas de mesma letra minúscula na linha e maiúscula na coluna não diferem pelo teste de Tukey (P>0,05). 
(PR) e AOL (Tabela 2) e os tratamentos não influenciaram essas variáveis.

O rendimento de carcaça é um importante parâmetro que muitas vezes torna-se a única avaliação utilizada na cadeia da comercialização da carne. Os dados referentes aos rendimentos encontrados neste estudo foram semelhantes aos registrados na literatura. De acordo com o revisado por ÝÁÑEZ (2002), os valores variaram entre 35 e $60 \%$. Esta alta variabilidade certamente foi devida à diferenciação nas metodologias empregadas por cada autor. Com relação aos valores encontrados para RCQ, estes foram próximos aos obtidos por COLOMER-ROCHER et al. (1992) para caprinos machos não-castrados pesando entre 5 e $115 \mathrm{~kg}$.

Os valores de RCQ e RCC observados nos animais de 30 dias de idade apresentaram-se superiores aos verificados em animais mais velhos. Isso ocorreu devido ao fato de estes animais ainda estarem em fase inicial de crescimento, não apresentando desenvolvimento total de suas vísceras e possuírem pouco conteúdo ruminal. Quanto aos dados referentes ao rendimento biológico, observouse que estes estiveram próximos a 59\%, pois seu cálculo tem como base o PCV e o conteúdo do TGI em animais entre 30 e 60 dias de idade, representou 5,8 e 19,9\% do $\mathrm{PCV}$, respectivamente.

De acordo com GAEBE et al. (1998), o RC e a AOL (área de olho de lombo) foram influenciados pelo processamento dos grãos da dieta fornecida aos bovinos em crescimento. Por outro lado, PETIT (2000) avaliou ovinos abatidos aos $47 \mathrm{~kg}$ e verificou que o processamento das dietas (inteiro x laminado) não influenciou $(\mathrm{P}>0,05)$ a IMS, o GPD, o peso final, o peso de carcaça e o rendimento e encontraram valores entre 47,4 e 47,9\% para RCQ. Avaliando a forma física da ração (farelada x peletizada) nas características de carcaça, NERES et al. (2001) verificaram que o uso de ração peletizada proporcionou aos cordeiros melhoria no RCQ e no RB de carcaça.

A perda por resfriamento apresentou valores (7\%) altos em relação aos obtidos por NERES et al. (2001), que foram de 3,19\% para cordeiros que receberam dieta peletizada. Provavelmente, a pequena cobertura de gordura existente na carcaça de animais jovens contribuiu para o aumento dessa perda. Não ocorreram diferenças $(\mathrm{P}<0,05)$ entre os tratamentos e entre as idades quanto a AOL e AOL/PCQ, sugerindo que a quantidade de músculo não diferiu. YÁÑEZ (2002) encontrou em cabritos Saanen de 5 e 20kg PV e alimentados à vontade valor de 0,89 para a relação AOL/ PCQ.

Não ocorreu interação significativa entre as variáveis idade e ração quanto ao $\mathrm{pH}$ zero hora e 24 horas (Tabela 3). O pH é um referencial importante pois afeta a qualidade da carne fresca, influenciando a cor, a CRA, a maciez e as características organolépticas da carne. Assim, observou-se, tal qual os relatos de MADRUGA et al. (1999), que, após o abate (zero hora), o pH variou entre 6,2 e 6,5 e não ocorreu diferença $(\mathrm{P}>0,05)$ entre as idades e entre as rações estudadas. Resultado semelhante foi observado por PI et al. (2005) em cabritos Boer em crescimento, onde o pH 1 hora e 24 horas, não diferiu entre animais alimentados com ração completa peletizada e não-peletizada.

Após 24 horas, foi verificado que os valores de $\mathrm{pH}$ oscilaram entre 5,6 e 6,0, valores estes próximos aos obtidos por BESERRA et al. (2001) e KANNAN et al. (2001). No presente trabalho, observou-se diferença $(\mathrm{P}<0,05)$ quanto ao $\mathrm{pH} 24$ horas entre as idades. Os animais abatidos aos 45 e 60 dias apresentaram $\mathrm{pH}$ menor do que os animais de 30 dias de idade, embora, provavelmente, os animais de todas as idades tenham apresentado reservas de glicogênio suficientes para transformar o músculo em carne, uma vez que foi

Tabela 2 - Médias, coeficientes de variação, interação entre idade e processamento de ração dos rendimentos de carcaça, perda por resfriamento e área de olho de lombo de cabritos Saanen alimentados com ração completa farelada (RCF), peletizada (RCP) ou extrusada (RCE) e abatidos aos 30, 45 e 60 dias de idade.

\begin{tabular}{|c|c|c|c|c|c|c|c|}
\hline \multirow{2}{*}{ Variáveis } & \multicolumn{3}{|c|}{ Idade } & \multicolumn{3}{|c|}{ Ração } & \multirow{2}{*}{$\mathrm{CV} \%$} \\
\hline & 30 & 45 & 60 & RCF & RCP & $\mathrm{RCE}$ & \\
\hline Rendimento carcaça quente (\%) & $55,85 a$ & $50,19 b$ & $50,20 b$ & 51,52 & 51,75 & 52,96 & 3,50 \\
\hline Rendimento comercial (\%) & $52,10 \mathrm{a}$ & $47,10 \mathrm{~b}$ & 47,30b & 48,10 & 47,95 & 48,60 & 4,70 \\
\hline Rendimento biológico (\%) & 59,34 & 59,37 & 58,71 & 59,24 & 58,60 & 59,95 & 4,10 \\
\hline Perda por resfriamento (\%) & 7,09 & 7,39 & 6,65 & 7,75 & 6,75 & 6,60 & 13,0 \\
\hline Área de olho lombo $\left(\mathrm{cm}^{2}\right)$ & 2,58 & 3,31 & 3,16 & 2,91 & 3,31 & 2,83 & 12,9 \\
\hline $\mathrm{AOL} / \mathrm{PCQ}\left(\mathrm{cm}^{2} / \mathrm{kg}\right)$ & 0,70 & 0,77 & 0,71 & 0,71 & 0,76 & 0,72 & 12,2 \\
\hline
\end{tabular}

Médias seguidas de mesma letra, na linha, não diferem pelo teste de Tukey $(\mathrm{P}>0,05)$.

Ciência Rural, v.37, n.2, mar-abr, 2007. 
Tabela 3 - Características físico-químicas da carne de cabritos Saanen alimentados com ração completa farelada (RCF), peletizada (RCP) ou extrusada (RCE) e abatidos aos 30, 45 e 60 dias de idade. Valores expressos na matéria natural.

\begin{tabular}{|c|c|c|c|c|c|c|c|}
\hline \multirow{2}{*}{ Variáveis } & \multicolumn{3}{|c|}{ Idade } & \multicolumn{3}{|c|}{ Ração } & \multirow{2}{*}{$\mathrm{CV} \%$} \\
\hline & 30 & 45 & 60 & RCF & RCP & RCE & \\
\hline pH zero hora & 6,5 & 6,2 & 6,3 & 6,2 & 6,2 & 6,3 & 3,5 \\
\hline pH 24 horas & $6,0 \mathrm{a}$ & $5,6 \mathrm{c}$ & $5,8 \mathrm{~b}$ & 5,8 & 5,7 & 5,8 & 3,0 \\
\hline$\%$ queda $\mathrm{pH}$ & 7,8 & 7,3 & 8,3 & 7,0 & 7,6 & 8,1 & 12,2 \\
\hline Cor: L* zero hora & 45,5 & 44,5 & 44,4 & 45,1 & 44,3 & 44,1 & 3,9 \\
\hline 24 horas & 46,7 & 47,5 & 47,1 & 46,6 & 47,0 & 47,7 & 5,4 \\
\hline a* zero hora & 9,2 & 9,5 & 10,3 & 10,0 & 9,44 & 9,6 & 11,4 \\
\hline 24 horas & $10,9 a$ & $11,2 \mathrm{a}$ & $9,5 b$ & 11,0 & 10,0 & 10,7 & 11,3 \\
\hline$b^{*}$ zero hora & 1,4 & 1,9 & 1,4 & 2,0 & 1,25 & 1,5 & 37,0 \\
\hline 24 horas & $5,8 a$ & $5,7 a$ & $3,4 \mathrm{~b}$ & 4,8 & 5,2 & 4,8 & 42,0 \\
\hline Razão a*/b*zero hora (\%) & $5,8 a$ & $5,8 a$ & $6,6 \mathrm{a}$ & $5,7 a$ & $6,8 a$ & $5,6 a$ & 43,0 \\
\hline Razão a*/b* 24 horas (\%) & $1,9 b$ & $2,1 \mathrm{a}$ & $2,9 a$ & $2,8 \mathrm{a}$ & $2,6 a$ & $2,5 a$ & 32,0 \\
\hline $\mathrm{CRA}^{1}$ & 63,0 & 63,8 & 65,0 & 64,6 & 63,3 & 64,7 & 5,5 \\
\hline Umidade & 77,7 & 78,0 & 77,9 & 77,7 & 78,0 & 77,8 & 2,0 \\
\hline Proteína & $16,5 c$ & $17,8 b$ & $19,5 \mathrm{a}$ & 18,3 & 18,0 & 17,8 & 5,8 \\
\hline Gordura & 1,92 & 1,98 & 1,90 & 1,96 & 1,86 & 1,99 & 16,0 \\
\hline Cinzas & 1,16 & 1,14 & 1,12 & 1,15 & 1,12 & 1,13 & 11,8 \\
\hline
\end{tabular}

${ }^{1}$ Capacidade de Retenção de água.

$\mathrm{L}^{*}$ (luminosidade), a* (teor de vermelho), b* (teor de amarelo).

Médias seguidas de mesma letra, na linha, não diferem pelo teste de Tukey $(\mathrm{P}>0,05)$.

observada porcentagem de queda de $\mathrm{pH}$ não significativa entre as idades.

Segundo OSÓRIO et al. (2000), a qualidade da carne apresenta modificações com a idade, em relação à composição e às características metabólicas dos músculos. De acordo com esses autores, a velocidade de queda do $\mathrm{pH}$ aumenta com a idade, gerando uma tendência em obter pHs mais baixos em animais com idade mais avançada. MADRUGA et al. (2002), embora não tenham avaliado os valores de $\mathrm{pH}$ no momento do abate, verificaram que o $\mathrm{pH}$ diminuiu $(\mathrm{P}<0,05)$ com o decorrer da idade, registrando valores de 6,58 e 6,10 para animais abatidos aos 175 e 310 dias, respectivamente.

Com relação à cor, verificou-se que a luminosidade e os teores de vermelho e amarelo não diferiram entre os tratamentos. KANNAN et al. (2001) verificaram valores de $L^{*}$, a* e b* de 42,5; 17,8 e 8,9 respectivamente, mensurados no músculo semimembranoso, 24 horas após o abate. PI et al. (2005) encontraram valores de $L^{*}$, a* e b* de 32,30; 19,85 e 3,63, respectivamente, no músculo Longissimus lumborum de cabritos alimentados com ração completa peletizada e tais valores não diferiram $(\mathrm{P}>0,05)$ dos encontrados em animais alimentados com ração completa não-peletizada.

Quanto à influência da idade na cor da carne, verificou-se que os valores de a* e b* 24 horas foram menores em animais de 60 dias, fato semelhante ao observado por SILVA SOBRINHO et al. (2005), no músculo semimembranoso de ovinos abatidos aos 300 dias, que apresentaram valores de $\mathrm{a}^{*} \mathrm{e} \mathrm{b}^{*}$ inferiores $(\mathrm{P}<0,05)$ aos abatidos aos 150 dias de idade. BONAGURIO et al. (2003) verificaram, tanto no músculo Longissimus dorsi, como no músculo semimembranoso, que os valores de $b^{*}$ diminuíram e os valores de a* elevaram-se com o aumento do peso de abate dos cordeiros.

As carcaças frias (24 horas) de animais com 30 dias de idade apresentaram valores de a*, b* e pH maiores em relação aos animais de 60 dias de idade, gerando provavelmente uma carne de coloração vermelho-escura. Esses dados corroboraram as afirmações feitas por SHIMOKOMAKI (2003), segundo as quais quanto menor o valor do $\mathrm{pH}$, mais clara é a cor da carne.

A razão a*/b* pode ser utilizada para estimar o teor de mioglobina de uma amostra (OLIVO, 2004). Assim, observou-se neste estudo que os teores de mioglobina da carne mensurados à zero hora não diferiram significativamente entre idades e entre rações. Portanto, a razão a*/b*obtida 24 horas após o abate foi maior em animais de 45 e 60 dias de idade do que em animais de 30 dias, indicando que esses animais mais velhos apresentaram carne com maior teor de mioglobina.

Ciência Rural, v.37, n.2, mar-abr, 2007. 
A água é o maior constituinte da carne e sua habilidade em reter umidade é muito importante para a manutenção de suas propriedades funcionais (OLIVO, 2004). Assim, com relação à CRA, não foram observadas diferenças $(\mathrm{P}>0,05)$ entre idades e entre rações e o valor médio de CRA obtido neste estudo foi de 64\%, indicando maciez e suculência à carne caprina. BESERRA et al. (2001) verificaram que a CRA da carne de caprinos SRD entre 20 e 22,9kg foi de 59\%.

Os tratamentos não influenciaram a composição centesimal da carne de cabritos entre 30 e 60 dias de idade. Verificou-se que não ocorreu interação significativa entre idade e processamento de_ração para nenhuma das variáveis analisadas. Com relação aos valores de umidade, verificou-se que não ocorreram diferenças significativas entre as idades e os tratamentos, sendo esses valores próximos aos obtidos na literatura (BESERRA et al., 2001; MADRUGA et al., 2002).

Quanto aos teores de gordura, além da carne caprina ser considerada uma carne magra, os valores encontrados neste estudo foram baixos, provavelmente devido aos animais terem sido avaliados até 60 dias de idade. De acordo com YÁÑEZ (2002), o incremento na taxa de crescimento do tecido adiposo ocorre a partir de $1,4 \mathrm{~kg}$ de peso de perna ( $21 \mathrm{~kg} \mathrm{PV})$. Os teores de gordura obtidos neste estudo foram inferiores aos obtidos por COLOMER-ROCHER et al. (1992) em cabritos Saanen, que foram de 9,9\% em carcaças de $10 \mathrm{~kg}$, e aos de BESERRA et al. (2001); MADRUGA et al. (2002), que foram de 4,87\% e 2,06\%, respectivamente. Verificou-se que, com o aumento da idade, ocorreu acréscimo nos teores de proteína, mas os teores de cinzas e gordura não foram alterados, sendo esses resultados semelhantes aos obtidos por MADRUGA et al. (2002) em caprinos mestiços com idades entre 175 e 310 dias. KIRTON (1970) relatou aumento no teor protéico de caprinos mais velhos. Em contrapartida, GAILI et al. (1972) reportaram que o conteúdo protéico apresentou decréscimo com o aumento da idade e do peso vivo.

\section{CONCLUSÕES}

Os processos de extrusão e peletização de ração completa não influenciaram o rendimento de carcaça, área de olho de lombo, peso de lombo, pescoço e as características físico-químicas da carne. Cabritos que receberam ração completa peletizada exibiram, aos 60 dias de idade, maiores peso final, peso de carcaça fria e pesos de paleta, costilhar e perna. Com relação ao efeito da idade, animais com 60 dias apresentaram carne com maior teor protéico, menor $\mathrm{pH}$ final, inferindo-se que essa seria a idade de abate mais adequada dentre as idades avaliadas.

\section{AGRADECIMENTOS}

Ao Conselho Nacional de Desenvolvimento Científico (CNPq), pelo apoio concedido ao trabalho (Processo: 140268/2002-2).

\section{REFERÊNCIAS}

AMARAL, C.M.C. et al. Performance and ruminal morphologic characteristics of Saanen kids fed ground, pelleted or extruded total ration. Small Ruminant Research, v.58, n.1, p.4754, 2005.

AOAC. Official Methods of analysis. 15.ed. Arlington, VA: Association of Official Analytical Chemists, 1990. v.1, p.69-70.

AFRC - AGRICULTURAL FOOD and RESEARCH COUNCIL. The nutrition of goats. Aberdeen: CAB International, 1998. 116 p.

BESERRA, F.J. et al. Características químicas e físico-químicas da carne de caprinos SRD com diferentes pesos de abate. Revista Tecnologia Carnes, v.3, n.2, p.1-7, 2001.

BONAGURIO, S. et al. Qualidade da carne de cordeiros Santa Inês puros e mestiços com Texel abatidos com diferentes pesos. Revista da Sociedade Brasileira de Zootecnia, v.32, n.6, p.1562-1570, 2003 (supl. 2).

COLOMER-ROCHER, F.C. et al. Carcass composition of New Zealand Saanen goats slaughtered at different weights. Small Ruminant Research, v.7, p.161-173, 1992.

EMBRAPA. Empresa Brasileira de Pesquisa Agropecuária. Embrapa Caprinos. Iniciando um pequeno grande negócio agroindustrial: processamento de carne caprina. Brasília: EMBRAPA, 2003. 106p.

GAEBE, R.J. et al. Effects of extruded corn or grain sorghum on intake, digestibility, weight gain and carcasses of finishing steers. Jornal of Animal Science, v.76, p.2001-2007, 1998.

GAILI, E.S.E. et al. A comparative study of some carcass characteristics of Sudan Desert sheep and goat. Animal Production, v.14, p.351-357, 1972.

HADJIPANAYIOTOU, M. Studies on the response of lactating Damascus goats to dietary protein. Journal of Animal Physiology and Nutrition, v.57, p.41-52, 1987.

HAMM, R. Biochemistry of meat hydratation. Advances in Food Research Cleveland, v.10, n.2, p.435-443, 1960.

KANNAN, G. et al. Color changes reflecting myoglobin and lipid oxidation in chevon cuts during refrigerated display. Small Ruminant Research, v.42, p.67-75, 2001.

KIRTON, A. H. Body and carcass composition and meat quality of the New Zealand Feral goat. New Zealand Journal Agriculture Research, v.13, p.167-181, 1970.

Ciência Rural, v.37, n.2, mar-abr, 2007. 
MADRUGA, M. S. et al. Efeito da idade de abate no valor nutritivo e sensorial da carne caprina de animais mestiços. Ciência e Tecnologia de Alimentos, v.19, n.3, p.374-379, 1999.

MADRUGA, M.S. et al. Influência da idade de abate e da castração nas qualidades físico-químicas, sensoriais e aromáticas da carne caprina. Revista da Sociedade Brasileira de Zootecnia, v.31, n.3, p.1562-1570, 2002. (Supl).

MORAND-FEHR, P.; LEBBIE, S.H.B. Proposals for improving the research efficiency in goats. Small Ruminant Research, v.51, p.145-153, 2004.

NERES, M.A. et al. Forma física da ração e pesos de abate nas características de carcaça de cordeiros em creep feeding. Revista da Sociedade Brasileira de Zootecnia, v.30, n.3, p.948-954, 2001. (supl. 1).

OLIVO, R. Atualidades na qualidade da carne de aves. Revista Nacional da Carne, v.28, n.331, p.38-50, 2004.

OSÓRIO, M.T.M. et al. Estudo do pH da carne em cordeiros Ideal criados em três sistemas de produção. In: REUNIÃO ANUAL DA SOCIEDADE BRASILEIRA DE ZOOTECNIA, 37., 2000, Viçosa. Anais... Viçosa: Sociedade Brasileira de Zootecnia, 2000. CD-ROM.

PETIT, H.V. Effect of whole and rolled corn or barley on growth and carcass quality of lambs. Small Ruminant Research, v.37, p.293-297, 2000.

PI, Z.K. et al. Effect of pretreatment and pelletization on nutritive value of rice straw-based total mixed ration, and growth performance and meat quality of growing Bôer goats fed on TMR. Small Ruminant Research, v.56, n.1-3, p.81-88, 2005.

POTCHOIBA, M. J. et al. Effects of all-milk diet on weight gain, organ development, carcass characteristics and tissue composition, including fatty acids and cholesterol contents, of growing male goats. Small Ruminante Research, v.3, p.583592, 1990.

RESENDE, K.T. et al. Metodologias de determinação da área de olho de lombo. In: REUNIÃO ANUAL DA SOCIEDADE BRASILEIRA DE ZOOTECNIA, 41., 2004, Campo Grande. Anais... Campo Grande: Sociedade Brasileira de Zootecnia, 2004a. CD-ROM.

SAS INSTITUTE. Statistics Analysis System. User's guide: statistics. Cary, 2001. 1 CD-ROM.

SHIMOKOMAKI, M. Princípios da qualidade de carne. In: SIMPÓSIO DE QUALIDADE DA CARNE, 2003, Jaboticabal. Anais... Jaboticabal: FUNEP, 2003. CD-ROM.

SILVA, R.R. O agronegócio brasileiro da carne caprina. Salvador: R.R. da Silva, 2002. 111p.

SILVA SOBRINHO, A.G. et al. Características de qualidade de carne de ovinos de diferentes genótipos e idades de abate. Revista da Sociedade Brasileira de Zootecnia, v.34, n.3, p.1070-1078, 2005.

YÁÑEZ, E.A. Desenvolvimento relativo dos tecidos e características da carcaça de cabritos Saanen, com diferentes pesos e níveis nutricionais. 2002. 85f. Tese (Doutorado em Zootecnia) - Faculdade de Ciências Agrárias e Veterinárias, Universidade Estadual Paulista, Jaboticabal. 